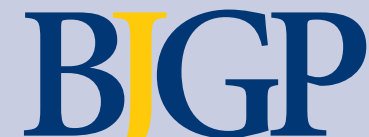

EDITOR

Roger Jones, DM, FRCP, FRCGP, FMedSci London

DEPUTY EDITOR

Alec Logan, FRCGP

Motherwell

JOURNAL MANAGER

Catharine Hull

SENIOR ASSISTANT EDITOR

Erika Niesner

ASSISTANT EDITOR

Moira Davies-Cinar

EDITORIAL ASSISTANT

Tania Marszalek

ADVERTISING EXECUTIVE

Brenda Laurent

EDITORIAL BOARD

Richard Baker, MD, FRCGP

Leicester

Stephen Barclay, MD, FRCGP, DRCOG

Cambridge

Chris Butler, MD, MRCGP

Cardiff

Kath Checkland, PhD, MRCGP

Manchester

Mark Gabbay, MD, FRCGP

Liverpool

Murray Lough, MD, FRCGP

Glasgow

David Mant, MD, FRCGP, FMedSci

Oxford

Nigel Mathers, MD, FRCGP, DCH

Sheffield

Tim Peters, MSc, PhD, CStat, FFPH

Bristol

Chris Salisbury, MD, FRCGP

Bristol

John Sandars, MSc, MD, FRCGP, MRCP

Leeds

Mark Shapley, FRCGP, DCH, DRCOG

Newcastle-under-Lyme

Niroshan Siriwardena, MMedSci, PhD, FRCGP

Lincoln

Theo Verheij, MD, PhD, MRCGP

Utrecht, The Netherlands

Sue Wilson, BA, PhD, PGA

Birmingham

2009 impact factor: 2.442

EDITORIAL OFFICE

1 Bow Churchyard, London, EC4M 9DQ

(Tel: 0203188 7400, Fax: 0203188 7401).

E-mail: journal@rcgp.org.uk

http://www.rcgp.org.uk/bjgp.aspx

PUBLISHED BY

The Royal College of General Practitioners,

1 Bow Churchyard, London, EC4M 9DQ.

Registered charity number 223106. The BJGP is

published by the RCGP, but has complete

editorial independence. Opinions expressed in the

BJGP should not be taken to represent the policy

of the RCGP unless this is specifically stated.

No endorsement of any advertisement is implied or intended by the RCGP.

PRINTED IN GREAT BRITAIN BY

HPM Limited, Prime House, Park 2000, Heighington

Lane Business Park

Newton Aycliffe, Co. Durham DL5 6AR.

Printed on $100 \%$ recycled paper

ISSN 0960-1643 (Print)

ISSN 1478-5242 (Online)

\title{
January Focus
}

\section{POPULATION MEDICINE}

This month Hannaford's group revisits the symptom iceberg, that mass of undeclared symptoms experienced in the community that lies below the waterline of medical consultation (page 12). They studied 2-week symptom recall in 2474 adults under 60 , half of whom had experienced one or more of a list of 25 symptoms offered to them, and found that individuals reported a mean of 3.66 different symptoms. There were predictable relationships between the number of symptoms experienced and a range of demographic parameters, with household income emerging as a notably strong associated factor; feeling tired, headaches, joint pain, and back pain were all reported by over $25 \%$ of responders. Almost $2 \%$ reported unintended weight loss, and $2.5 \%$ have seen blood in their stools. Most of these symptoms will never have become the subject of a medical consultation, but their sheer ubiquity emphasises the need to carefully consider the politically sensitive question of improving access to primary care.

Chronic illness was also strongly associated with reporting more symptoms, although this relatively young population would be likely to have less chronic illness than within a wider age range. The increasingly important topic of comorbidity is examined by Salisbury and colleagues (page 18), who found that 16\% of patients (those with more than one chronic condition as defined by the Quality Outcomes Framework) account for 32\% of all general practice consultations and, using a wider definition of chronic illness, the $58 \%$ of patients who have multimorbidity are responsible for $78 \%$ of consultations. Longitudinal continuity of care was found to be less in those with comorbidity.

The challenges of providing adequate primary care structures to deliver effective chronic disease management are explored in a European study involving 10 countries by van Lieshout and colleagues (page 25), who identified the adequacy of the electronic patient record and practice computer systems as crucial ingredients of effective care. Chronic disease management also appeared to be enhanced in countries such as Finland and Spain, where health centres tend to be larger and employ more doctors and other staff. The importance of the electronic medical record - this time in supporting preventive medical activities - is emphasised in a French study by Blanquet and co-workers (page 32).

If you had thought that the use of antidepressants in the management of depression is straightforward, read our opposing discussion papers on the topic - Middleton and Moncrieff leave us with the slogan 'unlikely to do any good and may do some harm' (page 47), while Anderson and Haddad advocate a careful assessment of the appropriateness of drug and non-drug interventions in individual patients (page 50). As GP commissioning consortia begin to emerge from the shadows of the NHS White Paper this will be an important topic of debate - how much pressure should we exert to ensure greater access to the psychological therapies? In a time of financial constraint, what are the short and long-term costs and benefits of pharmacotherapy and psychological treatments?

Commissioners of services also need an evidence base on which to base decisions about end-of-life care. Stephen Barclay has highlighted a series of gaps in our knowledge about the needs of terminally ill patients and the different arrangements that may be required for patients dying of cancer and non-cancer diseases, such as heart failure (page 53). Barclay identifies a series of questions that represent a substantial research agenda for primary care in this extremely important field.

Reporting the first steps in an inspiring initiative, Graham Watt's first 'Deep End' article introduces a series on providing care for the most socioeconomically deprived people in Scotland, involving 100 practices caring for over 430000 patients (page 66).

We hope that global health and an increasingly international perspective will find their way into the Journal in future, and Thompson and Ballard's call to action for general practice to become much more engaged in promoting a 'low-carbon healthcare system' will resonate with many (page 3). Another consideration for commissioners of services, as well as for our interactions with individual patients.

\section{Roger Jones \\ Editor}

(c) British Journal of General Practice 2011; 61: 1-80. 